\title{
Transcervical resection of two parathyroid adenomas located on the anterior mediastinum
}

\author{
Osman Toktaș1, Ümit Iliklerden', Baran Yerlikaya', Çetin Kotan', Abdussamet Batur²
}

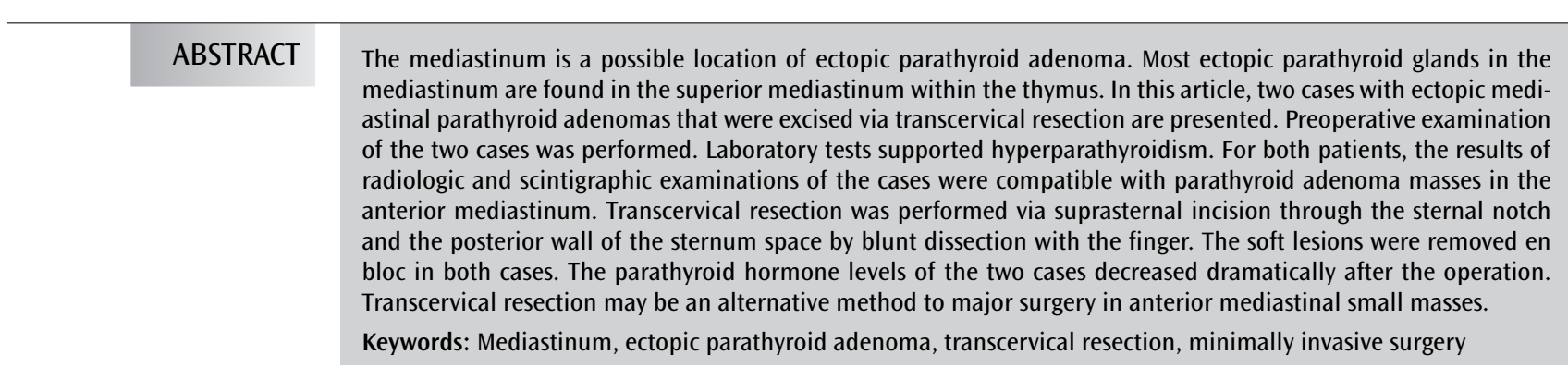

\section{INTRODUCTION}

Primary hyperparathyroidism is accompanied by oversecretion of parathormone, leading to hypercalcemia and hypophosphatemia. The major cause of primary hyperparathyroidism is parathyroid adenoma. In some patients, adenomas can be found ectopically. The mediastinum is an ectopic location for parathyroid adenomas (1). Parathyroid glands are ectopically positioned in almost in $15 \%-20 \%$ of cases (2). Retrospective studies have demonstrated that $1 \%-3 \%$ of all patients experiencing parathyroid operations have functional mediastinal parathyroid tumors $(2,3)$

Most of these tumors are found in the superior aspect of the anterior or posterior mediastinum and are thus permeable through a cervical incision; $1.4 \%-20 \%$ of patients require sternotomy (4). This may require surgical intervention in the form of parathyroidectomy, which is workable through a cervical incision in most cases; however, $1 \%-2 \%$ of these patients may require a transsternal or transthoracic approach due to a deeply seated mediastinal parathyroid gland $(1,5)$. Minimally invasive strategies have lately been found to be an alternative to traditional open approaches due to their lower morbidity and improved results. We describe our experience with a minimally invasive versus a traditional open approach for ectopic mediastinal parathyroidectomy.

\section{CASE PRESENTATIONS}

\section{Case 1}

A 40-year-old woman (Table 1) with high levels of calcium, phosphate, and parathormone was referred to our clinic for suspected primary hyperparathyroidism. There was no relevant medical or family history. Physical examination was normal. Abnormal calcium, parathormone, and phosphate levels were detected in blood analysis. At presentation, her biochemical levels were as follows: serum calcium and phosphorus levels were $11.6 \mathrm{mg} / \mathrm{dL}$ (normal range (NR) $8.8-10.2 \mathrm{mg} / \mathrm{dL}$ ) and $1.85 \mathrm{mg} / \mathrm{dL}$ (NR 2.7-4.5 $\mathrm{mg} / \mathrm{dL}$ ), respectively. Her intact parathormone level was $882 \mathrm{pg} / \mathrm{mL}$ (NR 15-68 pg/mL). Her thyroid function test results were within the normal range. The thyroid gland appeared normal, and no other pathologic lesion was found by cervical ultrasonography (USG) or magnetic resonance imaging (MRI). Ectopic parathyroid adenoma was suspected, and a mediastinal mass was identified in a chest computer tomography (CT) scan. CT study of the thorax revealed a nodule, $2 \times 3 \mathrm{~cm}$ in diameter, located on the anterior mediastinum superior to the aortic arch (Figure 1, 2). By technetium-99 m pertechnetate methoxy-isobutyl-isonitrite (Tc-99 m MIBI) scan, the nodule was seen as an intense focus in the anterior mediastinum, and ectopic parathyroid adenoma was diagnosed. After surgery, the patient's intact parathyroid hormone level reverted to $86 \mathrm{pg} / \mathrm{mL}$.

\section{Case 2}

A 57-year-old woman (Table 1) was referred to our clinic from another center for suspected primary hyperparathyroidism. She had been experiencing common bone pain and nephrolithiasis. Her symptoms had become more severe over time. At presentation, her biochemical levels were as follows: serum calcium $11.7 \mathrm{mg} / \mathrm{dL}$, 


\begin{tabular}{|c|c|c|c|c|c|c|c|}
\hline Patient data & Sex & Age & Size $(\mathrm{cm})$ & $\begin{array}{c}\text { Pre-op } \\
\text { serum PTH } \\
(15-68 \mathrm{pg} / \mathrm{mL})\end{array}$ & $\begin{array}{c}\text { Pre-op } \\
\text { serum Ca } \\
(8.8-10.2 \mathrm{mg} / \mathrm{dL})\end{array}$ & $\begin{array}{c}\text { Post-op } \\
\text { PTH }\end{array}$ & Post-op Ca \\
\hline Case 1 & $\mathrm{~F}$ & 40 & $3 \times 2 \times 1.5$ & 882 & 11.6 & 86 & 8.6 \\
\hline Case 2 & $\mathrm{~F}$ & 57 & $3 \times 3 \times 2$ & 1412 & 11.7 & 126 & 10 \\
\hline
\end{tabular}

PTH: parathyroid hormone; Ca: calcium

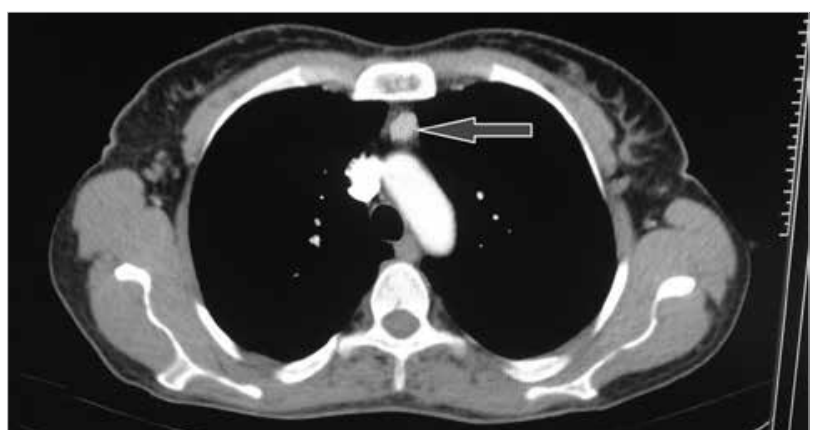

Figure 1. Axial contrast-enhanced CT imaging shows an ectopic parathyroid adenoma, $1.5 \mathrm{~cm}$ in diameter, located on anterior mediastinum (arrow)

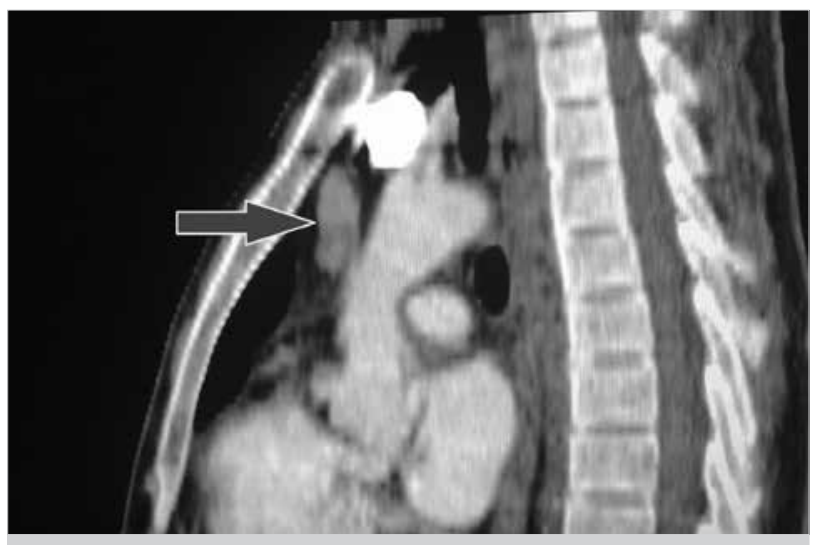

Figure 2. Sagittal contrast-enhanced CT imaging shows a small mass located in front of the arcus aorta (arrow)

parathyroid hormone $1412 \mathrm{pg} / \mathrm{mL}$, and phosphorus level $2.67 \mathrm{mg} /$ dl. The thyroid gland appeared normal, and no other pathologic lesion was found by cervical USG. Ectopic parathyroid adenoma was suspected, and a mediastinal mass was identified in a chest CT scan. CT study of the thorax revealed a nodule, $32 \times 20 \mathrm{~mm}$ in diameter, located posterior to the manubrium sterni and in front of the left brachiocephalic vein. By Tc-99 m MIBI scan, the nodule was seen as an intense focus in the anterior mediastinum, and ectopic parathyroid adenoma was diagnosed. After the operation, the patient's intact parathyroid hormone level reverted to $126 \mathrm{pg} / \mathrm{mL}$.

In both cases, rapid PTH was not considered due to the absence of rapid PTH facilities at the center. Postoperative pathologic diagnosis was parathyroid adenoma. A whole-body Tc99 $\mathrm{m}$ sestamibi parathyroid scan showed an increased tracer concentration in the anterior mediastinum, which suggested the presence of active parathyroid tissue, while the same activity was not observed in the neck. Thorax CT was performed after the sestamibi parathyroid scan. The level of the lesion is of great importance in these cases because lesions under the
A written informed consent was obtained from each patient.

\section{Surgical Approach}

Both patients underwent the same procedure. The patients were in the supine position under general anesthesia. The neck was brought to hyperextension to ensure maximum exposure. The skin and subcutaneous soft tissues were passed via a $3 \mathrm{~cm}$ transverse incision made from the sternal notch entrance. A sharp and blunt dissection was performed from the anterior mediastinum through the substernum (Figure 3a). It was descended to the lesion level located on the anterior mediastinum. The adenoma was held with Babcock forceps and was ligated from the surrounding fatty tissue with a LigaSure Atlas vessel sealing instrument (Valleylab; Tyco Healthcare Group LP Boulder, CO) (Figure 3b). The adenoma was removed en bloc (Figure 4). As the dissection of the substernal area was performed through adipose tissue, no bleeding or soft tissue injury occurred. The operation was terminated after hemostasis. Histopathological examination results of the specimens were compatible with parathyroid adenoma.

\section{DISCUSSION}

Churchill was the first to recognize hyperfunctioning ectopic parathyroid glands in 1932. The patient, Captain Charles E. Martell, underwent six prior unsuccessful cervical explorations and had severe osteitis fibrosa cystica until the ectopic gland was removed by a transsternal approach (1). Primary hyperparathyroidism is accompanied by hypersecretion of parathyroid hormone, which results in hypercalcemia and hypophosphathemia. Parathyroid adenoma is the major cause in most cases. In $11 \%-25 \%$ of cases, ectopic mediastinal hyperfunctional parathyroid tissue can be found (3).

Two different mediastinal parathyroid glands have been defined in the literature: the first type originates in the neck and descends into the chest with continuing glandular enlargement in the presence of negative intrathoracic pressure; the second type is the outcome of developmental malascent, which usually affects the inferior parathyroid glands or is due to supernumerary parathyroid glands. The first type can be removed by the transcervical approach; the second is usually deeply rooted in the mediastinum and may require an additional or an alternative access, either transsternal or transthoracic (1).

Diagnosis of ectopic mediastinal parathyroid glands is difficult, and their localization is even more so. The methods used to identify ectopic parathyroid glands include chest CT scan, MRI, or MIBI scan (1). If the parathyroid adenoma is located in the mediastinum, median sternotomy, thoracotomy, mediastinotomy, mediastinoscopy, or thoracoscopy may be required for resection, similar to other mediastinal masses (6-8). Successful and accurate preoperative localization of the ectopic glands is important, especially if minimally invasive approaches are 

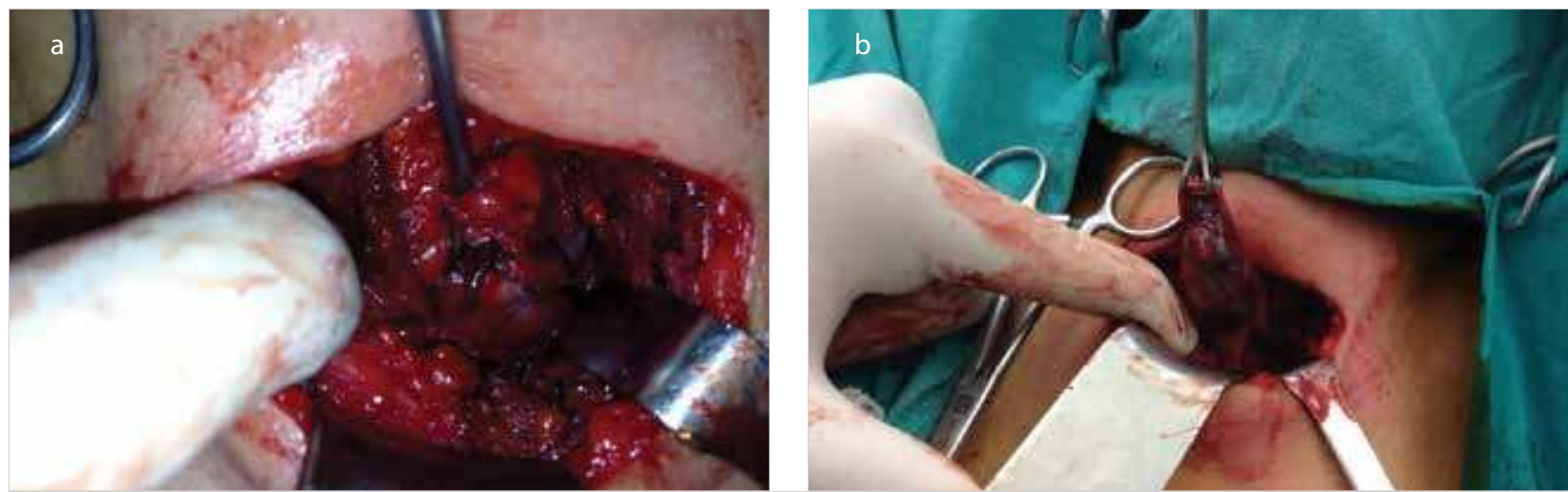

Figure 3. a, b. (a) A sharp and blunt dissection was performed from anterior mediastinum through substernum, (b) Adenoma was kept with bebcoock forceps and removed

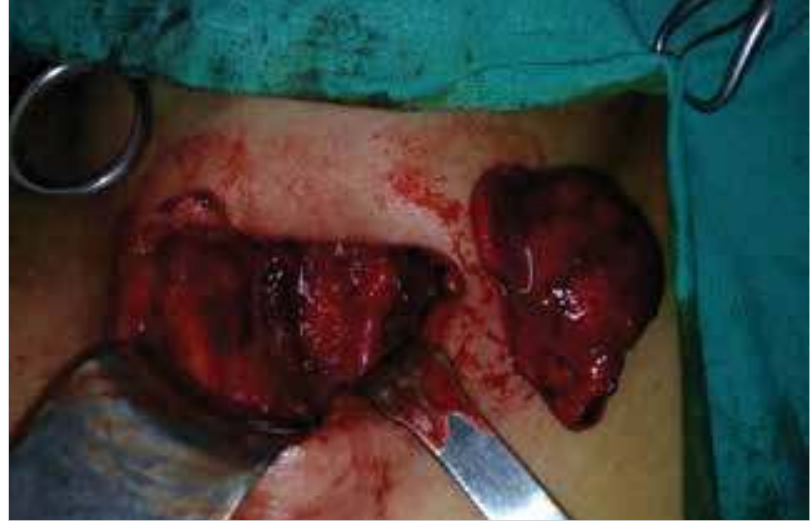

Figure 4. Adenoma was removed en block

considered (1). $98 \%$ of these mediastinal parathyroid adenomas are resectable through a neck collar incision, whereas $2 \%$ require a different approach (9). In such cases, it is important to plan the operation to enable complete surgical resection of the ectopic parathyroid adenoma.

The traditional approaches to ectopic mediastinal parathyroid glands include median sternotomy or thoracotomy to access the ectopic glands. Recently, minimally or less invasive approaches are being seen as alternatives, with reported lower morbidity and earlier return to normal life (1). The diverse minimally or less invasive strategies reported in the literature include splitting the manubrium (manubriotomy), closed mediastinal exploration with dedicated equipment followed by excision of the gland via transcervical approach, video-assisted mediastinoscopy, video-assisted thoracoscopic surgery (VATS), and robot-assisted exploration $(1,10)$. Surgery is the preferred treatment. Surgical excision should be planned based on thorax CT and parathyroid scintigraphy findings. In such cases, cervical incision can also be applied (3). The transcervical approach was applied for our patients; parathyroidectomy was completely successful, with no complications.

\section{CONCLUSION}

Minimally invasive surgery for upper mediastinal parathyroidectomy is safe and can be applied with low morbidity. It may be equivalent to the traditional open approach in terms of morbidity; however, it provides the patient with a significantly shorter length of hospital stay.
Informed Consent: Written informed consent was obtained from patient who participated in this study.

Peer-review: Externally peer-reviewed.

Author Contributions: Concept -O.T., Ç.K., Ü.I.; Design - O.T., A.B., Ç.K.; Supervision - Ü.I., B.Y., O.T.; Resource - B.Y.,Ü.I., O.T., A.B.; Materials - O.T., Ç.K., A.B.; Data Collection and/or Processing - A.B., O.T., B.Y.; Analysis and/or Interpretation - Ü.I., B.Y.,O.T., A.B.; Literature Search - O.T., A.B.; Writing Manuscript - O.T., A.B.; Critical Reviews - Ç.K., A.B.

Conflict of Interest: The authors have no conflicts of interest to declare.

Financial Disclosure: The authors declared that this study has received no financial support.

\section{REFERENCES}

1. Liman ST, Topcu S, Dervisoglu E, Gorur GD, Elicora A, Burc K, et al. Excision of ectopic mediastinal parathyroid adenoma via parasternal videomediastinoscopy. Ann Thorac Cardiovasc Surg 2014; 20: 67-69. [CrossRef]

2. Said SM, Cassivi SD, Allen MS, Deschamps C, Nichols FC 3rd, Shen $\mathrm{KR}$, et al. Minimally invasive resection for mediastinal ectopic parathyroid glands. Ann Thorac Surg 2013; 96: 1229-1233. [CrossRef]

3. Soler R, Bargiela A, Cordido F, Aguilera C, Arqüeso R, Cao I. MRI of mediastinal parathyroid cystic adenoma causing hyperparathyroidism. J Comput Assist Tomogr 1996; 20: 166-168. [CrossRef]

4. Boushey RP, Todd TR. Middle mediastinal parathyroid: diagnosis and surgical approach. Ann Thorac Surg 2001; 71: 699701. [CrossRef]

5. Alesina PF, Moka D, Mahlstedt J, Walz MK. Thoracoscopic removal of mediastinal hyperfunctioning parathyroid glands: personal experience and review of the literature. World J Surg 2008; 32: 224-231. [CrossRef]

6. Ott MC, Malthaner RA, Reid R. Intraoperative radioguided thoracoscopic removal of ectopic parathyroid adenoma. Ann Thorac Surg 2001; 72: 1758-1760. [CrossRef]

7. Tcherveniakov P, Menon A, Milton R, Papagiannopoulos K, Lansdown M, Thorpe JAC. Videoassisted mediastinoscopy (VAM) for surgical resection of ectopic parathyroid adenoma. J Cardiothorac Surg 2007; 2: 41. [CrossRef]

8. Semik M, Netz B, Schmidt C, Scheld HH. Surgical exploration of the mediastinum: mediastinoscopy and intraoperative staging. Lung Cancer 2004; 45: S55-61. [CrossRef]

9. Wei B, Inabnet W, Lee JA, Sonett JR. Optimizing the minimally invasive approach to mediastinal parathyroid adenomas. Ann Thorac Surg 2011; 92: 1012-1017. [CrossRef]

10. Nilubol N, Beyer T, Prinz RA, Solorzano CC. Mediastinal hyperfunctioning parathyroids: incidence, evolving treatment, and outcome. Am J Surg 2007; 194: 53-56. [CrossRef] 